\title{
A Case of Pancreatic Neuroendocrine Tumor presenting Iron Deficiency Anemia in a Patient with Neurofibromatosis Type 1
}

\author{
Xueyu Sun ${ }^{1}$, Yanan Yu1 ${ }^{1}$, Yueping Jiang ${ }^{1}$, Deming Li ${ }^{1}$
}

${ }^{1}$ Department of Gastroenterology, The Affiliated Hospital of Qingdao University Medical College, Qingdao, Shandong 266003, P.R. China

\begin{abstract}
Neurofibromatosis type 1 (NF1) is a dominantly inherited disease characterized by cafe'-au-lait spots in the skin and dermal neurofibromas. We report an unusual case of a 38-year-old women with NF1 presented with abdominal pain and iron deficiency anemia. Imaging studies revealed a lesion in the head of the pancreas. At surgery, a $20 \mathrm{~mm}$ neuroendocrine tumor was found in the head of the pancreas. We present this case of a patient with pancreatic neuroendocrine tumors (PNETs) associated with NF1 and review the literatures that have been reported to discuss the characteristics of these tumors to improve early differential.
\end{abstract}

Keywords: Neurofibromatosis Type 1; Von Recklinghausen's Disease; Neuroendocrine Tumor; Pancreatic Neuroendocrine Tumor; Carcinoma; Familial Syndrome

\section{Introduction}

Neurofibromatosis type 1 (NF1), also called von Recklinghausen's disease, is an autosomal dominant inherited disease with an incidence at birth of 1:3000 and a prevalence of 1:4000-5000 $0^{[1]}$. The main clinical characteristics of the disease are cafe'-au-lait spots in the skin and dermal neurofibromas ${ }^{[2]}$.This multisystem disorder caused by a mutation in the NF 1 gene which has been identified on chromosome 17q11.2 $2^{[1]}$. The NF1 gene is a tumor suppressor, so the mutation of this gene results in loss of the corresponding protein function and the consequent development of benign or malignant tumors ${ }^{[3]}$.

Neuroendocrine tumors(NETs) are a group of tumors originated from diffuse neuroendocrine system, which can occur in many organs of the body.
Gastroenteropancreatic neuroendocrine tumors (GEP-NETs) are mostly sporadic and a few concurrent with some familial syndromes. Depending on the occurrence or absence of clinical symptoms because of excess hormonal secretion, pancreatic neuroendocrine tumors are generally divided into functional or nonfunctional PNETs.

\section{Case report}

A 38-year-old woman with NF1 presented with 1 year of intermittent epigastric pain and an aggravation for the last 2 months. An abdominal contrast-enhanced computed tomography (CT) scan, that the patient underwent in other hospital, showed a cyst in the head of the pancreas, accompanied by tortuous dilated pancreatic duct except for a short segment of stenosis. Then, she was admitted to our hospital for further

This article is published under the terms of the Creative Commons Attribution License 4.0 Author(s) retain the copyright of this article. Publication rights with Alkhaer Publications. Published at: http://www.ijsciences.com/pub/issue/2017-03/

DOI: 10.18483/ijSci.1210; Online ISSN: 2305-3925; Print ISSN: 2410-4477 
diagnosis and treatment. On physical examination, she presented with some cafe'-au-lait spots on her skin and multiple neurofibromas over her whole body(figure 1). Laboratory tests displayed that the hemoglobin, mean corpuscular volume (MCV) and mean cellular hemoglobin concentration ( MCHC) levels were lower than the lower limit of the normal value, suggesting that she had iron deficiency anemia. The other laboratory data were almost within the normal ranges. Upper gastrointestinal endoscopy revealed a partial swollen mucosa with a granular surface on the nipple side of the second part of the duodenal. The biopsy contained a few nests of neoplastic cells in the mucosa, and a neuroendocrine tumor was considered by the immunohistochemistry. Endoscopic ultrasonography (EUS) demonstrated a low echoic mass in the head of the pancreas, measuring $41 \mathrm{~mm}$ in greatest diameter, had invaded into the adjacent duodenum and the layers of the duodenal wall were not clear( figure 2 ). That was thought as the most likely source of her iron deficiency anemia. The pancreatic duct which located in the pancreatic body and tail was dilated and the widest part measured $12 \mathrm{~mm}$. No obvious dilatation of the common bile duct. Review of an abdominal contrast-enhanced CT was performed and suggested that the mass in the head of the pancreas was less uniform density and the boundary between the mass and the duodenal wall was not clear(figure 3 ). Lymph nodes surrounding them were swollen, with a maximal diameter of $11 \mathrm{~mm}$. No tumor was found in the liver or the wall of the stomach. A subtotal stomach-preserving Whipple procedure was performed., that confirmed a tumor ,20 $\mathrm{mm}$ in greatest diameter, in the head of the pancreas. Several biopsy specimens of the pancreas lesion confirmed the mass was a neuroendocrine tumor. On immunohistochemical examination, the lesion cells were strongly positive for synaptophysin, chromogranin $\mathrm{A}$ and a Ki-67 index of 2\%(figure 4).
According to the WHO classification (2010), the tumor was diagnosed as "pancreatic neuroendocrine tumor, PNET G2". At follow-up 4 months after the surgery, return-visit revealed no evidence of disease progression.

\section{Discussion}

We describe an unusual case of a patient with NF1 complicated by PNET that presented with abdominal pain and iron deficiency anemia. NF1 is one of the most common dominantly inherited disease that affecting multiple systems. It has four main diagnostic signs which are visible in the skin, such as cafe'-au-lait spots, dermal neurofibromas, plexiform neurofibromas and axillary freckles. Among them, the first two are most common ${ }^{[2]}$. NETs are a heterogeneous group of tumors, which are arising from the neuroendocrine cells all over the body. About 5-10\% of GEP-NETs occur in the background of a genetic syndrome ${ }^{[4]}$.To date, at least ten inherited syndromes predisposing to endocrine tumors, such as multiple endocrine neoplasia type 1 and $2(\text { MEN1 and MEN2 })^{[5]}$, Von Hippel-Lindau syndrome (VHL), neurofibromatosis type 1 (NF1), hyperparathyroidism-jaw tumor syndrome and tuberous sclerosis. MEN1 and MEN2 are considered to be the major exciting cause to benign and malignant endocrine tumors ${ }^{[6]}$. Among the patients with NF1, the most common is the neuroendocrine tumors of the duodenum and ampulla, but the incidence of PNETs is very $\operatorname{rare}^{[7]}$. To our case, this is the ninth case has been reported since 1964 .

NF1 is caused by the mutation of the NF1 gene, which is located in the chromosome 17. The protein named neurofibromin, that the NF1 gene encodes, is a negative regulator of Ras pathway, especially for mammalian target of rapamycin( mTOR )function , and the overactivation may be a key to the neuroendocrine ${ }^{[8]}$. That cause the development of 
A Case of Pancreatic Neuroendocrine Tumor presenting Iron Deficiency Anemia in a Patient with Neurofibromatosis Type 1

benign or malignant tumors. A review of the world's medical literature from 1964 to 2016 revealed only eight cases of PNETs concurrent with NF1 have previously been reported(Table 1$)^{[9-16]}$. Among these nine patients, all the 2 cases of somatostatinomas were located at the head of the pancreas, and all the 4 cases of insulinomas were located at body or tail of the pancreas. The other three have no hormone secretion, called non-functional pancreatic neuroendocrine tumor(NF-PNETs) according to the 2010 World Health Organization (WHO) classification, also occurred in the head of the pancreas. Clinical symptoms are mainly related to the hormones that the tumor secreted. The insulinomas occurs Episodic hypoglycemia because of the role of insulin. The somatostatinomas' Clinical symptoms include abdominal pain, jaundice and weight loss, that may owing to the malignancy of the tumor itself or the common bile duct being compressed by the tumor. In our case, the patient has iron deficiency anemia, and we consider that because a chronic blood loss caused by mucosal bleeding when the pancreatic tumor invaded the duodenal wall. Surgery is still the best choice for treatment, although lymph node metastasis has occurred.

In summary, NF1 patients have an incremental incidence of neuroendocrine tumors, although its incidence is rare. Clinicians should know this correlate as part of the differential diagnosis in patients with NF1 who present with gastrointestinal symptoms.

\section{References}

1. Agaimy A, Vassos N, Croner R S. Gastrointestinal manifestations of neurofibromatosis type 1 (Recklinghausen's disease): clinicopathological spectrum with pathogenetic considerations. Int J Clin Exp Pathol. 2012. 5(9):852-862.

2. Uusitalo E, Leppävirta J, Koffert A, et al. Incidence and mortality of neurofibromatosis: a total population study in Finland. J Invest Dermatol. 2015. 135(3): 904-906.

3. Reynolds R M, Browning G G P, Nawroz I, Campbell I W. Von Recklinghausen's neurofibromatosis: neurofibromatosis type 1. Lancet. 2003. 361: 1552-1554.

4. Anlauf M, Garbrecht N, Bauersfeld J, et al. Hereditary neuroendocrine tumors of the gastroenteropancreatic system. Virchows Arch. 2007. 451 Suppl 1: S29-38.

5. Gut P, Komarowska H, Czarnywojtek A, et al.Familial syndromes associated with neuroendocrine tumours. Contemp Oncol (Pozn). 2015. 19(3): 176-183.

6. Crona J, Skogseid B. GEP- NETS UPDATE: Genetics of neuroendocrine tumors. Eur J Endocrinol. 2016. 174(6): R275-290.

7. Relles D, Baek J, Witkiewicz A, Yeo CJ. Periampullary and duodenal neoplasms in neurofibromatosis type 1: two cases and an updated 20-year review of the literature yielding 76 cases. J Gastrointest Surg. 2010. 14(6): 1052-1061.

8. Katsinelos P, Lazaraki G, Chatzimavroudis G. An unusual case of obscure gastrointestinal bleeding in a patient with neurofibromatosis type 1. Clin Gastroenterol Hepatol. 2015. 13(3): A24-25.

9. Coskey R L, Tranquada R E. Insulinoma and Multiple Neurofibromatosis : Report of a Case. Metabolism. 1964. 13(4): 312 .

10. Fung J W, Lam K S. Neurofibromatosis and insulinoma. Postgrad Med J. 1995. 71: 485-486.

11. Fujisawa $\mathrm{T}$, Osuga $\mathrm{T}$, Maeda $\mathrm{M}$, et al. Malignant endocrine tumor of the pancreas associated with von Recklinghausen's disease. J Gastroenterol. 2002. 37:59-67.

12. Perren A, Wiesli P, Schmid S, et al. Pancreatic endocrine tumors are a rare manifestation of the neurofibromatosis type 1 phenotype: molecular analysis of a malignant insulinoma in a NF-1 patient. Am J Surg Pathol. 2006. 30(8): 1047-1051.

13. Takai A, Setoyama T, Miyamoto S. Pancreatic somatostatinoma with von Recklinghausen's disease. Clin Gastroenterol Hepatol. 2009. 7(5): A28.

14. Bukkems SF, Stoot JH, Driessen A, Beets-Tan RG, van Nieuwenhoven MA, Masclee AM. A rare cause of obstructive jaundice and weight loss in Von Recklinghausen's disease. Neth J Med. 2010. 68(12): 414-417.

15. Nishi T, Kawabata Y, Hari Y, et al. A case of pancreatic neuroendocrine tumor in a patient with neurofibromatosis-1. World J Surg Oncol. 2012. 10: 153.

16. Rogers A, Wang LM, Karavitaki N, Grossman AB. Neurofibromatosis Type 1 and pancreatic islet cell tumours: an association which should be recognized. QJM. 2012. 108(7): 573-576. 
Table 1. Reported patients with PNET associated with NF1

\begin{tabular}{|c|c|c|c|c|c|}
\hline Reference & Year & Gender & Age & $\begin{array}{l}\text { Tumor Position in } \\
\text { pancreas }\end{array}$ & $\begin{array}{l}\text { Tumor } \\
\text { size }\end{array}$ \\
\hline Coskey R L ${ }^{[9]}$ & 1964 & Female & 66 & Body and Tail & $\mathrm{n} / \mathrm{a}$ \\
\hline Fung $\mathrm{J} \mathrm{W}^{[10]}$ & 1995 & Male & 45 & Body and Tail & $35 \mathrm{~mm}$ \\
\hline Fujisawa $\mathrm{T}^{[11]}$ & 2002 & Female & 66 & Head & $20 \mathrm{~mm}$ \\
\hline Perren A ${ }^{[12]}$ & 2006 & $\mathrm{n} / \mathrm{a}$ & $\mathrm{n} / \mathrm{a}$ & Body & $\mathrm{n} / \mathrm{a}$ \\
\hline Takai A ${ }^{[13]}$ & 2009 & Male & 48 & Head & $20 \mathrm{~mm}$ \\
\hline $\begin{array}{l}\text { Bukkems SF } \\
\text { [14] }\end{array}$ & 2010 & Male & 48 & Head & $35 \mathrm{~mm}$ \\
\hline Nishi $T^{[15]}$ & 2012 & Male & 62 & Head & $40 \mathrm{~mm}$ \\
\hline Rogers A ${ }^{[16]}$ & 2012 & Female & 75 & Body & $15 \mathrm{~mm}$ \\
\hline Presence & 2016 & Female & 38 & Head & $20 \mathrm{~mm}$ \\
\hline
\end{tabular}

Continued Table 1. Reported patients with PNET associated with NF1

\begin{tabular}{|c|c|c|c|c|}
\hline Reference & Symptom & Diagnosis & Metastasis & Prognosis \\
\hline Coskey R L ${ }^{[9]}$ & $\mathrm{n} / \mathrm{a}$ & Insulinoma & $\mathrm{n} / \mathrm{a}$ & $\mathrm{n} / \mathrm{a}$ \\
\hline Fung J W ${ }^{[10]}$ & Episodic hypoglycemia & Insulinoma & NO & $\mathrm{n} / \mathrm{a}$ \\
\hline Fujisawa $\mathrm{T}^{[11]}$ & $\begin{array}{l}\text { Weight loss } \\
\text { Abdominal pain }\end{array}$ & $\begin{array}{l}\text { Neuroendocrine } \\
\text { tumors }\end{array}$ & Lymph node & Alive \\
\hline Perren A ${ }^{[12]}$ & $\mathrm{n} / \mathrm{a}$ & Insulinoma & $\mathrm{n} / \mathrm{a}$ & $\mathrm{n} / \mathrm{a}$ \\
\hline Takai A ${ }^{[13]}$ & $\begin{array}{l}\text { Loss of appetite , } \\
\text { Weight loss }\end{array}$ & $\begin{array}{l}\text { Somatostatinom } \\
\text { a }\end{array}$ & Liver & Alive \\
\hline $\begin{array}{l}\text { Bukkems } \quad \text { SF } \\
{[14]}\end{array}$ & $\begin{array}{l}\text { Jaundice、Diarrhea、 } \\
\text { Weight loss }\end{array}$ & $\begin{array}{l}\text { Somatostatinom } \\
\text { a }\end{array}$ & Lymph node & Alive ( 2 years ) \\
\hline Nishi $T^{[15]}$ & $\mathrm{n} / \mathrm{a}$ & $\begin{array}{l}\text { Neuroendocrine } \\
\text { tumors }\end{array}$ & NO & Alive ( 2 years ) \\
\hline Rogers $A^{[16]}$ & $\begin{array}{l}\text { Episodic hypoglycemia , } \\
\text { Fainting }\end{array}$ & Insulinoma & NO & $\begin{array}{l}\text { Alive ( } 6 \\
\text { months ) }\end{array}$ \\
\hline Presence & Anemia & $\begin{array}{l}\text { Neuroendocrine } \\
\text { tumors }\end{array}$ & NO & $\begin{array}{l}\text { Alive } \quad 3 \\
\text { months })\end{array}$ \\
\hline
\end{tabular}



Type 1

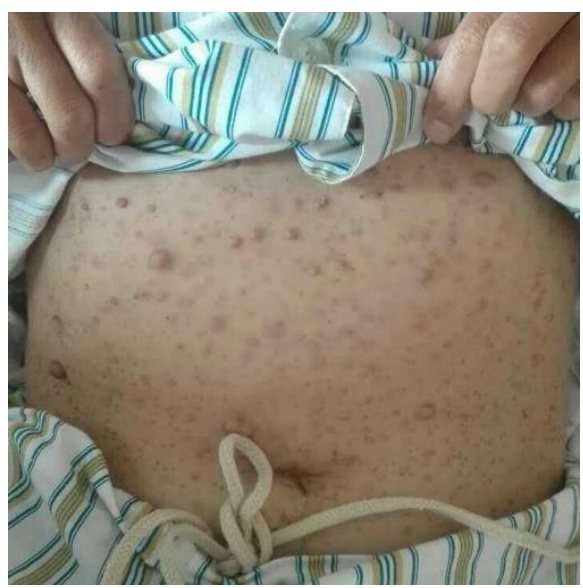

figure 1. A view of the abdomen of the patient. Numerous café-au-lait spots and multiple neurofibromas on her skin.

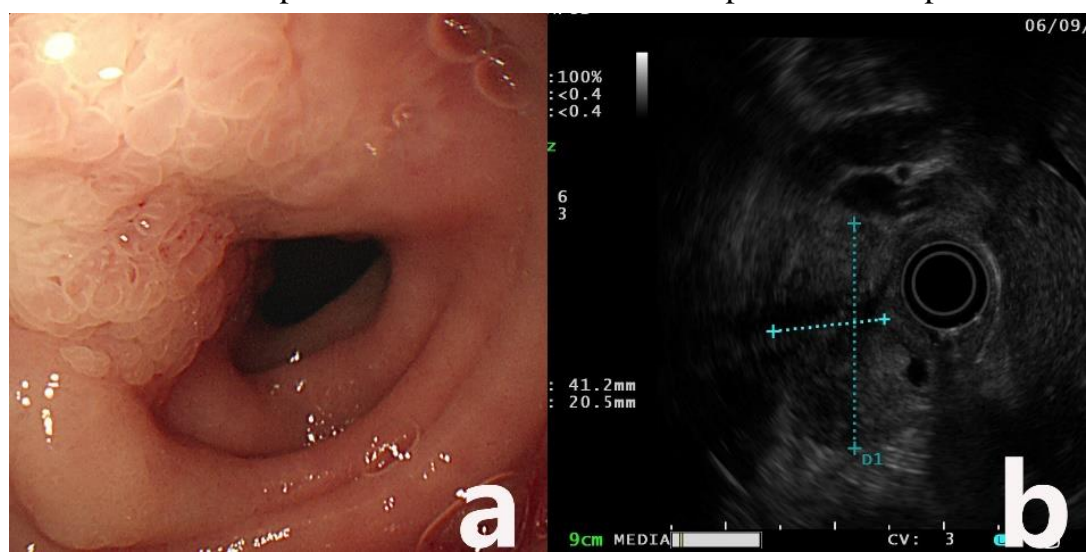

Figure 2. a. Under endoscopy we can see the mucosa near the papilla of the descending duodenum is swollen. b. Under EUS we can see a low echoic mass in the head of the pancreas, measuring $41 \mathrm{~mm}$ in greatest diameter.

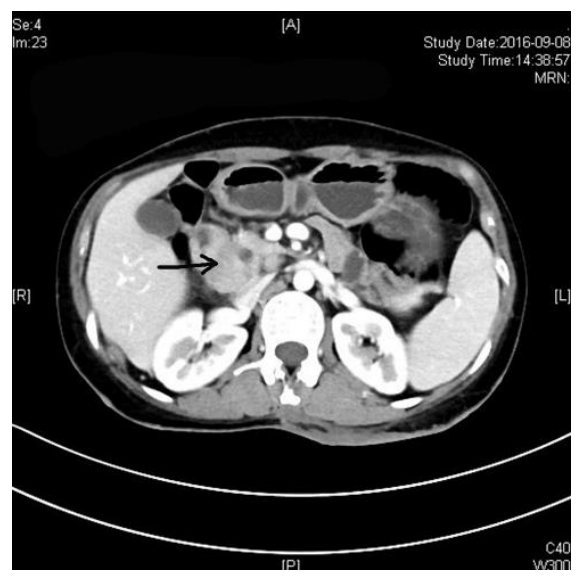

figure 3. Abdominal contrast-enhanced CT shows the tumor(arrow) in the head of the pancreas was less uniform density and the boundary between the tumor and the duodenal wall was not clear. 
A Case of Pancreatic Neuroendocrine Tumor presenting Iron Deficiency Anemia in a Patient with Neurofibromatosis Type 1

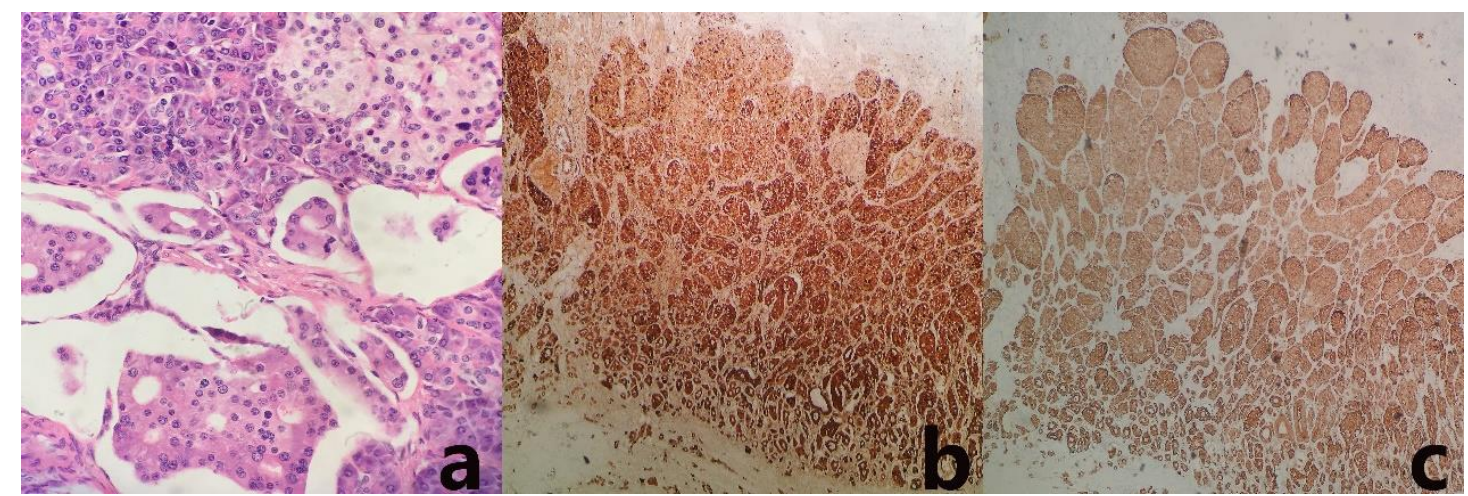

figure 4. a. Histological examination showed the distinctive histologic features of an endocrine tumor, i.e., uniform, large polygonal-to-columnar cells with abundant granular cytoplasm. Magnification $\times 400$. b. Immunohistochemical staining showed that the tumor was positive for chromogranin A. Magnification $\times 200$. c. Immunohistochemical staining showed the tumor was positive for synaptophysin. Magnification $\times 200$. 